\title{
Environment Governance, Sustainable Livelihood and Indigenous Knowledge in Ethnic Tourism Villages of China
}

\author{
Qianlang Shang, ${ }^{1}{ }^{*}$, Mengxue $\mathrm{Li}^{\mathbf{1}}$ and Huanhuan Wang1 \\ ${ }^{1}$ Tourism and Cultural Industry Research Institute, Yunnan University of Finance and Economics, Kunming, Yunnan, China
}

\begin{abstract}
The rapid expansion of tourism in Chinese ethnic areas has promoted changes in livelihood activities and ecosystems. Ethnic indigenous knowledge has played an essential role in environmental governance and sustainable livelihood. The paper integrates local knowledge theory with the Sustainable Livelihood Approach (SLA) framework, proposes cultural capital as a critical component of livelihood capital, and illustrates the influence of indigenous knowledge on sustainable livelihood by analyzing how indigenous knowledge transforms into cultural livelihood capital typical cases. The research results show that excavation and utilization of indigenous knowledge can increase the family cultural livelihood capital, optimize the choice of family livelihood strategy, and improving the level of environmental governance, which ultimately affects the sustainability of family livelihood. Finally, the paper puts forward some suggestions on using indigenous knowledge to govern the tourism community.
\end{abstract}

\section{Introduction}

China has considered tourism development as an essential policy for reducing rural poverty [1]. Cultural tourism in ethnic villages of China has developed rapidly, which has promoted the transformation of traditional family livelihood mode to tourism operation [2]. The research shows that cultural tourism can diversify livelihoods [3]. Besides, the changes involving livelihood assets from natural, economic, human, social, and cultural aspects are interrelated and interactive, forming new evolution characters of ethnic community [4]. In this process, a variety of family livelihood modes in ethnic villages have emerged. Simultaneously, changes in livelihood activities and lifestyles may indicate the dynamism of culture in study villages [3]. The sustainable livelihood of families is related to the realization of residents sharing the fruits of tourism development and rural revitalization and great significance to China's ethnic groups' unity and stability.

However, research finds that while tourism promotes the transformation of traditional livelihood mode, it is easy to cause problems such as family re-poverty after poverty alleviation, livelihood vulnerability, and ecological vulnerability. High dependence on tourism as the single livelihood option can reduce sustainability [2]. For ethnic areas, indigenous knowledge is closely related to family livelihood changes and acculturation [5]. In particular, the culture and regional environment of ethnic villages are particular, and the traditional indigenous knowledge is relatively intact so that the livelihood change will interact with the indigenous knowledge system.

Simultaneously, it is a considerable problem connecting modern enterprise management systems with traditional local culture in tourism community governance. Many cases indicate that the modern management system in tourism enterprises is often not acclimated in the implementation, which focuses on conflicts in tourism development. Furthermore, all these problems show that indigenous knowledge, as an essential part of traditional culture, plays a vital role in local tourism's sustainable livelihood and community governance. Indigenous knowledge should be further research at this time.

Then, how does the indigenous knowledge theory integrate into the analytical framework of sustainable livelihood theory? How can indigenous knowledge be transformed into household livelihood capital? What will be the impact on sustainable household livelihoods? The research on these problems has high theoretical and practical value. Around these problems, this paper will build the ethnic tourist villages sustainable livelihood theory analysis framework, guided by national tourism village family livelihood sustainable issues, introducing indigenous knowledge theory into sustainable livelihood research. The paper taking tourist villages as examples analyzes the influence of indigenous knowledge on family livelihood sustainability and puts forward the inspiration of sustainable family livelihood based on indigenous knowledge.

\section{Literature review on indigenous knowledge and sustainable livelihood}

The Sustainable Livelihood Approach (SLA) originated from the research on farmers' poverty alleviation and gradually formed a normative theoretical and analytical paradigm. People believe that livelihood is a way of making a living, and sustainable livelihood means recovering from shocks and providing livelihood opportunities for future generations [6]. Some international organizations and institutions proposed the

\footnotetext{
*Corresponding Author: shangqianlang@ynufe.edu.cn
} 
Sustainable Livelihood Approach (SLA) analytical framework, and sustainable livelihood gradually attracted extensive attention from scholars [7]. Some scholars have applied the sustainable livelihood theory to tourism research earlier. The scholars considered that sustainable livelihood provided a more comprehensive perspective to understand tourism development and eliminate poverty [8] Furthermore, procedures, methods, and sustainable livelihood analytical framework of tourism were constructed $[9,10]$.

Although SLA has developed distinct advantages over other methods, the neglect of cultural factors is considered a major disappointment of SLA [11]. Some scholars believe that the critical point of sustainable livelihood in its early stage is to pay attention to the connection between environmental issues and livelihood, and culture, as an essential resource in rural areas, is generally ignored.

Indigenous knowledge is an essential traditional cultural resource in ethnic villages, and the relationship between indigenous knowledge and sustainable livelihood has gradually attracted people's attention. The research finds that the new means of livelihood derived from the transformation of indigenous knowledge brought better life and development to ethnic women [12]. The tourism livelihoods could integrate with traditional livelihood in rhythm to achieve sustainability as well [13]. Tourism helps change local people's attitudes toward conserving biodiversity and reducing people's dependence on natural resources [14]. Some people even explored the traditional cultural adaptation of residents in transforming livelihood mode in ethnic tourism communities [5].

Based on the research, the traditional culture plays an essential role in the tourism development and livelihood sustainability of ethnic villages. However, SLA research does not pay enough attention to the cultural factors. SLA framework has considerable potential to expand the connotation of culture. Therefore, this paper takes the traditional ethnic village Jinglai in Yunnan as a case and puts forward traditional cultural elements into the SLA framework. Then, it discusses the impact that local traditional indigenous knowledge has on sustainable livelihoods in the family, discusses the feasibility of "cultural capital" as an essential component of livelihood capital, and puts forward the practical implications of sustainable livelihood based on indigenous knowledge.

\section{Theoretical Framework and Research Method}

\subsection{Cultural capital and SLA framework}

Traditional SLA framework includes five parts: Vulnerability context, Livelihood assets, Transforming structures \& processes, Livelihood strategies, and Livelihood outcomes, among which livelihood assets are the core of the framework. The SLA framework divides livelihoods assets into five categories: human capital, natural capital, financial capital, physical capital, and social capital.

Cultural capital reflects the unique knowledge and ability of ethnic village communities and residents to make a living. Thus this paper includes cultural capital into the livelihood assets in the SLA framework (Fig.1). In traditional ethnic villages, cultural capital is the cultural resource for people to make a living, including heritage, traditional customs, indigenous knowledge.

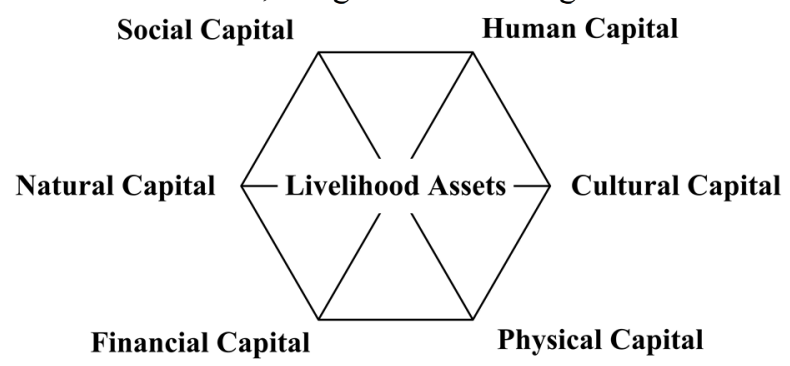

Fig. 1 Livelihood Assets

\subsection{Jinglai Village and Indigenous knowledge}

Jinglai ethnic village is in Xishuangbanna Dai Autonomous Prefecture, Yunnan Province, southwest of China. It was selected in the second batch of Traditional Chinese Villages List in 2013, and tourism Villages with Ethnic characteristics in Yunnan Province in 2015. In 2018, Jinglai was included in National 4A Tourist Attractions. Jinglai established an "Enterprise-oriented" development model depending on the management experience that the tourism group had on scenic area management and project developing, taking the business model "Village + Enterprises + Residents" led by enterprises, participated by residents.

The application of traditional indigenous knowledge is the main feature of tourism development and community governance in Jinglai. On the one hand, the beautiful natural scenery and unique ethnic and cultural customs have become a critical tourist landscape. The scenic area has carefully built the ethnic landscape and excavated and developed the ethnic culture. On the other hand, traditional indigenous knowledge is applied to community governance. The village regulations, which the scenic spot company formulated, and the village, become the institutional norms for scenic spots and village governance. Through village regulations, companies, villages, and villagers' rights and obligations in scenic spots are clarified, which has produced sound governance effects on protecting traditional dwellings, alienated buildings, and the sale of prohibited items.

\subsection{Data sources and analyzing methods}

This paper mainly obtained data utilizing stakeholders' interviews, household surveys, and participatory observation. Semi-structured interviews and collective interviews were primary ways taken in interviews. The author has conducted preliminary, formal, and tracking investigations in Jinglai in March 2018, July 2018, and May 2019. The total number of stakeholders and insiders in the interviews was 24, and each interview lasted about one to two hours. According to the household livelihood capital, livelihood strategy, and livelihood outcome involved in the sustainable livelihood analysis framework, 
this study designed a questionnaire with 23 types of questions in 5 parts and 54 valid questionnaires (48\% of the total) obtained. The Likert Scale measured the data.

Considering the construction and measurement of an index, the computational formula of livelihood capital is:

$$
C_{i}=\sum_{j=1}^{m} W_{j} X_{S_{i j}}
$$

In the formula (1), $C_{i}$ represents the value of livelihood capital of sample $i ; W_{j}$ represents the weight of $\mathrm{j} ; X_{S_{i j}}$ is the standardized value of sample $\mathrm{i}$ under index $\mathrm{j} ; \mathrm{m}$ is the index number

Standardized value is nondimensionalized by range standardization, and the formula is:

$$
X_{S_{i j}}=\left(X_{i j}-X_{j_{\min }}\right) /\left(X_{j_{\max }}-X_{j_{\min }}\right)
$$

In the formula (2), $X_{S_{i j}}$ represents the standardized value of sample $\mathrm{i}$ with index $\mathrm{j} ; X_{i j}$ is the value of sample $\mathrm{i}$ with index $\mathrm{j} ; X_{j_{\max }}$ is the maximum of index $\mathrm{j}$, and $X_{j_{\min }}$ is the minimum of index $\mathrm{j}$

In formula (1), using principal component analysis, the weight formula is:

$$
W_{P C A}=\frac{M}{N}
$$

In formula (3), $\mathrm{M}$ is the scoring coefficient of primary factors, $\mathrm{N}$ is the characteristic root; the index weight is determined according to all capital types, and $W_{P C A}$ needs to be normalized to obtain the corresponding index weight. The specific result was calculated by statistical software SPSS22.0.

\section{Research results}

\subsection{Indigenous knowledge and Cultural Livelihood Capital of Jinglai}

The rational use of indigenous knowledge could become the cultural livelihood capital of families in tourism development. As far as families in Jinglai are concerned, traditional culture represented by traditional handcraft skills, traditional national delicacies, and characteristic tourism commodities has become an essential part of tourism management activities, which has enhanced the tourism attraction value and economic value of traditional culture and increased the livelihood capital capacity of families.

\subsubsection{Traditional handicrafts used in the tourism cultural products}

The traditional handicrafts of Jinglai Village are developed as essential tourist products of the scenic spot. A designated handicraft display place has been constructed. After a survey on villagers familiar with handcrafting, Jinglai scenic spot hired 13 villagers and their family members in designated places to display 13 types of traditional skills, including pattern-leaf culture, cloth dyeing, Dai medicine, sugaring, bamboo weaving. Some traditional handicrafts have been heritage by local people, some have been re-developed after studying and training.

\subsubsection{Cultural dissemination of traditional national food}

The traditional food of Dai is also a major attraction for foreign tourists and an essential skill for farmers who set up angertainment and restaurants. Tourist groups that come to Jinglai through travel agencies start from Jinghong in the morning and visit Daluo Port after arriving in Daluo Town. After that, many travel agencies arrange for tourists to have meals in the village. Most of the families that run farmhouses and restaurants in Jinglai are good at cooking, and some even ask villagers from nearby villages to help with the cooking.

\subsubsection{Featured tourism products enrich cultural capital.}

The sale of tourist products is the leading way for most families in Jinglai to develop cultural tourism products. As Jinglai is located on the border, many of the goods are bought directly from Myanmar by villagers. Villagers mostly set up stalls selling tourist commodities inside their villages, which can only be set up indoors and are not allowed to occupy main roads. The price of all commodities is marked clearly by the company unified identification card.

\subsection{Indigenous knowledge, sustainable livelihood and environment governance}

The application of traditional indigenous knowledge has become an important tourist attraction in ethnic villages. It can expand the choice of family livelihood strategy, enrich the diversity of local family livelihood activities, and improve residents' enthusiasm and income. More importantly, the formulation and implementation of the village regulations and agreements have greatly improved community governance and provided an excellent external environment for sustainable livelihood.

\subsubsection{Indigenous knowledge influences family livelihood strategy}

Table 1. Family livelihood capital under different livelihood strategies

\begin{tabular}{ccc}
\hline $\begin{array}{c}\text { Livelihood } \\
\text { assets }\end{array}$ & $\begin{array}{c}\text { Livelihood strategies } \\
\text { Tourism } \\
\text { livelihood } \\
\text { Strategies }\end{array}$ & $\begin{array}{c}\text { Diverse } \\
\text { livelihood } \\
\text { strategies }\end{array}$ \\
\hline Human capital & 0.141 & 0.130 \\
Natural capital & 0.068 & 0.063 \\
Physical capital & 0.113 & 0.109 \\
Social capital & 0.169 & 0.179 \\
Financial capital & 0.040 & 0.045 \\
Cultural capital & 0.074 & 0.071 \\
Total capital & 0.605 & 0.597 \\
\hline
\end{tabular}


Families with more traditional skills tend to choose the tourism livelihood strategy. Most families with traditional Dai skills in Jinglai Village have become the traditional craft display points in the scenic spot. On the one hand, these villagers display crafts in the form of work and earn wages. On the other hand, they can carry out other tourism business activities by taking advantage of many tourists. According to the measurement of household livelihood capital (Tab. 1), the family's livelihood capital value based on tourism operation is greater than that of the family with multiple livelihood strategies. Families with more cultural capital have more advantages in tourism operation and livelihood strategy choices and are more likely to benefit from tourism development, thus improving the overall level of family livelihood capital.

\subsubsection{Traditional culture enrich the diversity of livelihood}

The scenic spot can reflect the characteristics of local traditional culture in tour guides, traditional entertainers, staff dress, and service facilities. The 13 ethnic handicraft display points in the scenic area represent the development of traditional cultural products. These residents participate in the display of ethnic culture in the scenic area. Moreover, they can start agricultural production and other business activities in the off-season and other spare time. The excavation of traditional culture can fully arouse residents' enthusiasm, increase the diversity of livelihood activities, and improve the sustainability of family livelihood.

\subsubsection{Community participation enhances family livelihood sustainability}

Jinglai scenic area has developed for quite a long time, and cultural tourism products are relatively mature. We can see the potential of residents to participate in the development of cultural products from the future development orientation and direction of scenic spots. Jinglai plans to build the scenic spot into the "enterprises + farmers + internet" model that concerns leisure products in rural tourism and new characteristic cultural, agricultural manors. Residents can participate in planting crops such as lotus fragrance, food production and sales, and production and management of agricultural estates in the planned new construction and construction projects, which will help residents participate in tourism operation and maintain a sustainable livelihood.

\subsubsection{Village regulations improve the environmental governance}

The combination of modern governance system and indigenous knowledge provides ways for community participation in tourism, enhances the community and residents' recognition of tourism development, improves environmental governance, and guarantees the fairness of livelihood activities. The establishment of village regulations and the "scenic spot management committee" in Jinglai results from active exploration. Scenic spots and villages take village regulations as a vital governance standard of scenic spots, combine the agreement's content with local culture, clarify their respective rights and obligations, and make up the gap between the governance system and local culture.

\section{Conclusion}

Indigenous knowledge is a valuable cultural resource in ethnic tourism areas and essential support for developing tourist cultural products. It is of great significance to the cultural inheritance and development of ethnic tourism in ethnic areas. Based on theoretical construction and case analysis, the research finds that:

1) Cultural capital is an integral part of livelihood assets. When incorporated into the SLA analysis framework, it can reflect the level of household livelihood assets more comprehensively in tourism development and remind people of the importance of traditional culture.

2) Reasonable use of indigenous knowledge can become an essential cultural livelihood asset for families in tourism development. Indigenous knowledge represented by traditional handicrafts, ethnic delicacies, and characteristic commodities has become an essential means for residents to participate in tourism development and enrich livelihood activities.

3) Indigenous knowledge also makes an essential contribution to promoting sustainable household livelihoods and environmental governance. The use of indigenous knowledge can optimize living strategy selection of residents, diversity livelihood activities, improve environmental governance, and the ways to safeguard community participation in tourism development.

The main contributions of this study are as follows: 1) Introducing the theory of indigenous knowledge into the system of sustainable livelihood theory, putting forward the importance of cultural capital, complementing the lack of sustainable livelihood theory in terms of culture, and further enriching the theoretical basis of SLA. 2) This paper analyses the relationship between indigenous knowledge, sustainable tourism development, and livelihood sustainability to provide theoretical support for sustainable livelihood and tourism research. 3) Analysing the relationship among indigenous knowledge, sustainable livelihood, and community governance through the case analysis method, which provides typical cases using indigenous knowledge under tourism development.

Indigenous knowledge contains the traditional wisdom of residents and is a summary of long-term local governance experience. This study has proved the significance of local knowledge for environmental governance and sustainable livelihoods. In future research, how indigenous knowledge participates in environmental governance and livelihood sustainability needs to be considered.

\section{Acknowledgments}

This research was supported by the National Natural Science Foundation of China "Study on the Family 
Livelihood Resilience of Ethnic Tourism Villages along the China-Myanmar Border: Multidimensional Measurements, Evolutionary Mechanisms, and Cooperative Governance" (72064039) and the Humanities and Social Sciences Research Project in 2020 of the Ministry of Education of China "Research on the Classification Evaluation and Realization Path of Family Sustainable Livelihood in Border Ethnic Tourism Villages from the Perspective of Indigenous knowledge" (20YJC630118).

\section{References}

1. Qian C, Sasaki N, Jourdain D, et al. Local livelihood under different governances of tourism development in China-A case study of Huangshan mountain area[J]. Tourism Management, 2017, 61: 221-233.

2. Su M M, Wall G, Xu K. Heritage tourism and livelihood sustainability of a resettled rural community: Mount Sanqingshan World Heritage Site, China[J]. Journal of Sustainable Tourism, 2016, 24(5): 735-757.

3. Mbaiwa J E, Sakuze L K. Cultural tourism and livelihood diversification: The case of Gcwihaba Caves and XaiXai village in the Okavango Delta, Botswana[J]. Journal of Tourism and Cultural Change, 2009, 7(1): 61-75.

4. Li Y, Yu H, Chen T, et al. Livelihood changes and evolution of upland ethnic communities driven by tourism: a case study in Guizhou Province, southwest China[J]. Journal of Mountain Science, 2016, 13(7): 1313-1332.

5. Zhang J, Liu X J, Sun J X. Traditional Cultural Adaptation of Residents in an Ethnic Tourism Community: Based on Personal Construction Theory[J]. Tourism Tribune,2019,34(02):16-28.
6. Chambers R, Conway G. Sustainable rural livelihoods: practical concepts for the 21st century[M]. Institute of Development Studies (UK), 1992.

7. Carney D. Sustainable livelihoods approaches: progress and possibilities for change[M]. London: Department for International Development, 2003.

8. [Tao T C H, Wall G. Tourism as a sustainable livelihood strategy[J]. Tourism Management, 2009, 30(1):90-98.

9. Simpson M C. Tourism, livelihoods, biodiversity, conservation and the climate change factor in developing countries[J]. Climate change and tourism: assessment and coping strategies, 2007.

10. Shen F, Hughey K F D, Simmons D G. Connecting the sustainable livelihoods approach and tourism: A review of the literature[J]. Journal of Hospitality and Tourism Management, 2008, 15(1): 19-31.

11. Daskon C, Binns T. Culture, tradition and sustainable rural livelihoods: exploring the culture-development interface in Kandy, Sri Lanka[J]. Community Development Journal, 2010, 45(4): 494-517.

12. Zhang J. Study on the Changes of Local Knowledge and Yao Women's Livelihood in the Context of Ethnic Tourism--A Case Study of Huangluo Yao Village in Longsheng County'Guangxi Province[J]. Tourism Tribune, 2011, 26(8).

13. Rongna A, Sun J. Integration and sustainability of tourism and traditional livelihood: A rhythmanalysis[J]. Journal of Sustainable Tourism, 2020, 28(3): 455-474.

14. Nyaupane G P, Poudel S. Linkages among biodiversity, livelihood, and tourism[J]. Annals of tourism research, 2011, 38(4): 1344-1366. 